\title{
Pesticide Amounts are Small in Streams in the Red River of the North Basin, 1993-94
}

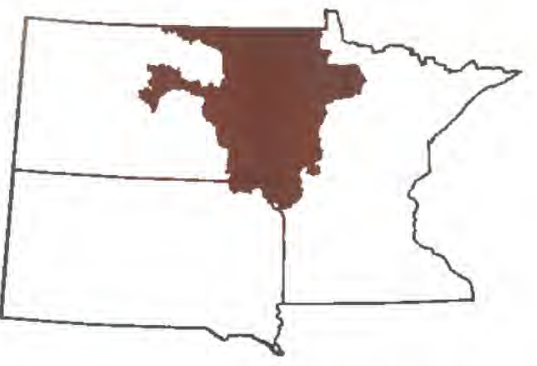

Pesticides were routinely sampled during 1993-94 from the sites shown below. Sites 1-3 were located in subbasins in which the principal crops are small grains, which is representative of principal crops in the Red River Basin. Site 4 represents flow from most of the basin. Site 5 was added in 1994 to sample water from the southern part of the basin.

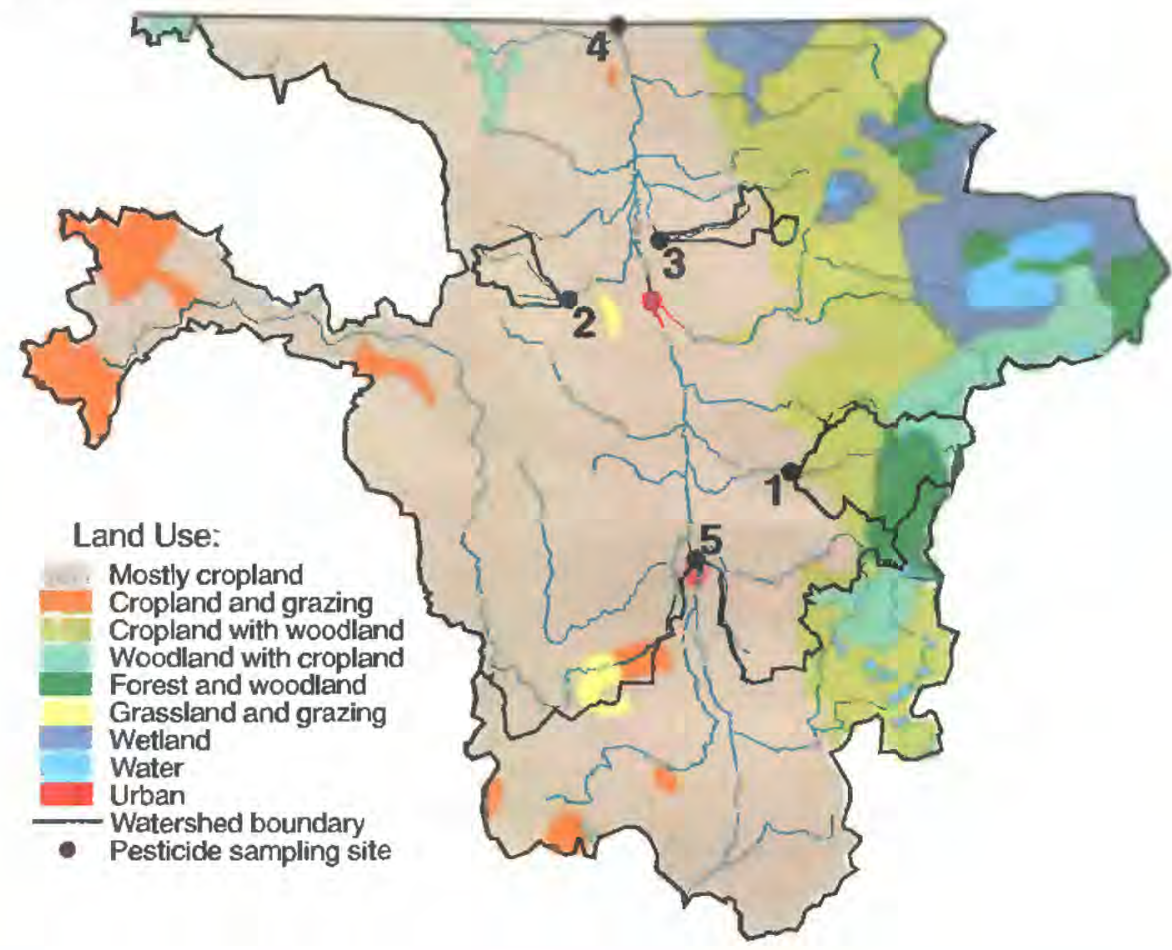

Site number and name

1 Wild Rice River at Twin Valley, Minn.

2 Turtle River near Arvilla, N.Dak.

3 Snake River near Alvarado, Minn.

4 Red River of the North at Emerson, Man.

5 Red River of the North upstream of

Fargo, N. Dak.
Pesticides are used extensively in the largely agricultural Red River of the North (Red River) Basin, but, unlike many other agricultural basins, only small amounts are routinely detected in samples from streams in the basin. The pesticides detected comprise less than 2 percent of the amount applied and usually are at concentrations far less than established drinking water standards. Most of the detected pesticides seem to come from sources near the headwaters in the southern part of the basin. Although low, concentrations are related to pesticide application and runoff. Flat land slope, organic soils, pesticide management, and degradation all may limit pesticide contamination that reaches Red River Basin streams. than average runoff, especially after pesticide application, than would occur normally. Flow and runoff in many of the streams during 1993 were well above normal during July through September and exceeded 10 times normal during August.

Pesticides analyzed in water samples (bold-faced compounds were detected in at least 2 percent of samples)

\begin{tabular}{|lll|}
\hline Acifluorfin & Dichlorprop & Norflurazon \\
\hline Alachlor & Dieldrin & Oryzalin \\
\hline Aldicarb & 2,6-Diethylanains & Oxamyl \\
\hline Aldicarb sulfone & Dimethoate & Parathion \\
\hline Aldicarb sulfoxide & Dinoseb & Pebulate \\
\hline Atrazine & Disulfoton & Pendimethalin \\
\hline Azinophos-methyl & Diuron & cis-Permethrin \\
Benfluralin & EPTC & Phorate \\
\hline Bentazon & Ethafluralin & Picloram \\
\hline Bromacil & Ethoprop & Prometon \\
\hline Bromoxynil & Fenuron & Pronamide \\
\hline Butylate & Fluometuron & Propachlor \\
\hline Carbaryl & Fonofos & Propanil \\
\hline Carbofuran & -HCH (in Lindane) & Propargite \\
\hline Carbofuran, 3-hydroxy & $\gamma$-HCH (Lindane) & Propham \\
\hline Chloramben & Linuron & Propoxure \\
\hline Chlorpyrifos & MCPA & Silvex \\
\hline Clopyralid & MCPB & Simazine \\
\hline Cyanazine & Malathion & 2,4,5-T \\
\hline 2,4-D (acid) & Methiocarb & Tebuthiuron \\
\hline 2,4-DB & Methomyl & Terbacil \\
\hline p,p'-DDE & Methyl parathion & Terbufos \\
\hline Dacthal (DCPA) & Metolachlor & Thiobencarb \\
\hline Dacthal (mono acid) & Metribuzin & Triallate \\
\hline Desethyl atrazine & Molinate & Triclopyr \\
\hline Diazinon & Napropamide & Trifluralin \\
\hline Dicamba & Neburon & \\
\hline
\end{tabular}

The pesticides detected in at least 50 percent of samples include atrazine, cyanazine, metolachlor, and triallate. The following graph shows atrazine and cyanazine concentrations measured at each of the sites. Of the sites sampled in 1993, higher concentrations of pesticides generally were found in the Red River at the Canadian border (site 4) than at the other streams sampled (sites 1-3). Sites 2 and 3 usually had very low concentrations - often near or below laboratory detection limits, although one sample from the Turtle River (site 2) had the highest concentrations of atrazine and cyanazine measured in this study.

The pesticides detected at site 4 are most often used on corn and soybeans, crops grown more commonly in the southern part of the

U.S. Geological Survey soybeans, small grains

The following table shows the pesticides that were analyzed in samples collected in the Red River Basin. All of these compounds can be quantified to 0.05 parts per billion or lower. Many of the pestiinclude 2,4-D, MCPA, bromoxynil, and trifluralin. streams of the Red River Basin, even during 1993-94. These years had unusually large amounts of rain, which produced much greater compounds were detected infrequently, and at low concentrations, in 
basin. It is likely that the pesticides measured at the Canadian border are entering the Red River from the southern parts of the basin.

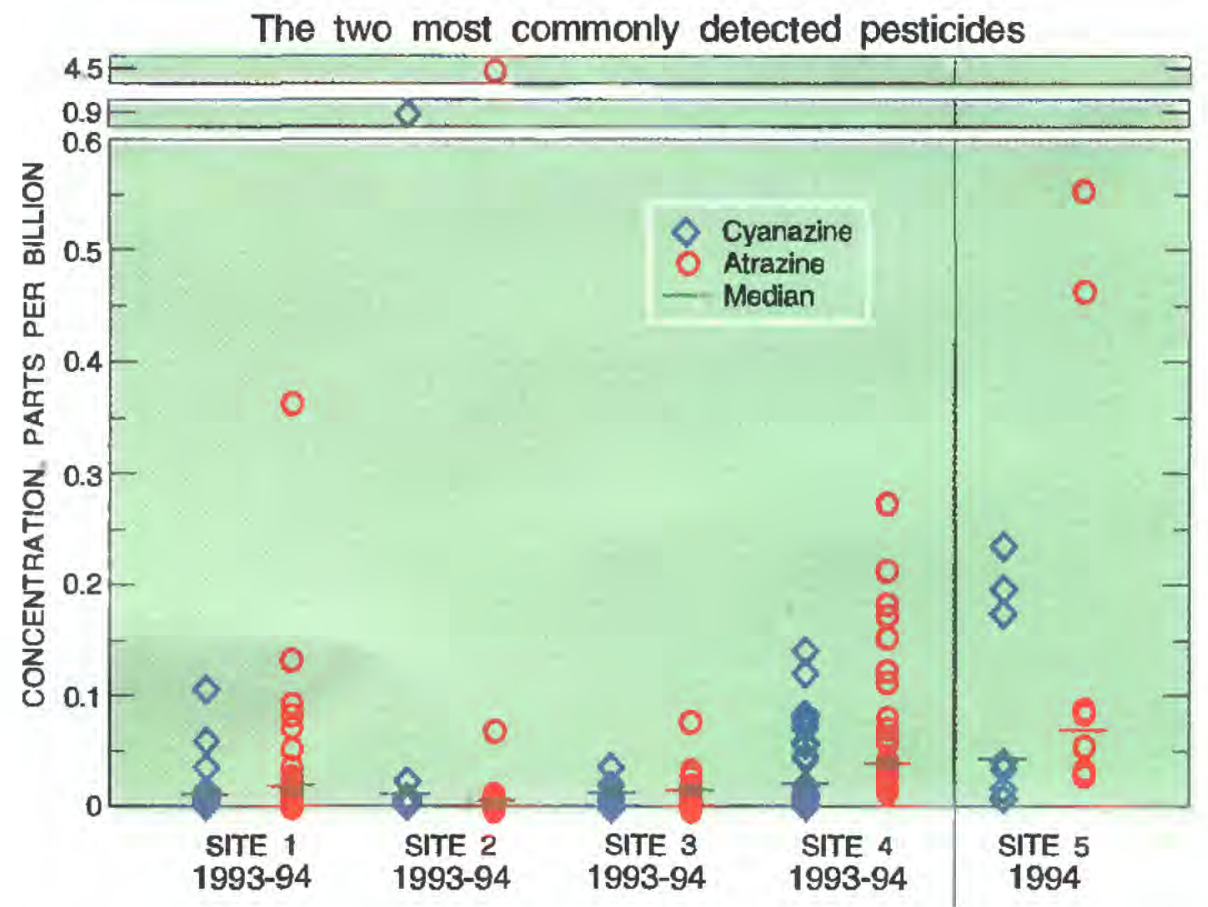

To verify the source of these pesticides, a sampling site was added in 1994 on the Red River upstream of Fargo-Moorhead (site 5). Concentrations of corn herbicides at site 5 were higher than at site 4. Concentrations were higher because they were less diluted by other water, indicating that these samples are closer to the source of the pesticides. Concentrations at site 5 usually were well below drinking water standards.

Although pesticide concentrations were quite low, they occasionally were high enough to evaluate their relation to application and runoff. The following graphs show the relations between atrazine and triallate concentrations and streamflow at sites 1 and 4 during 1993.

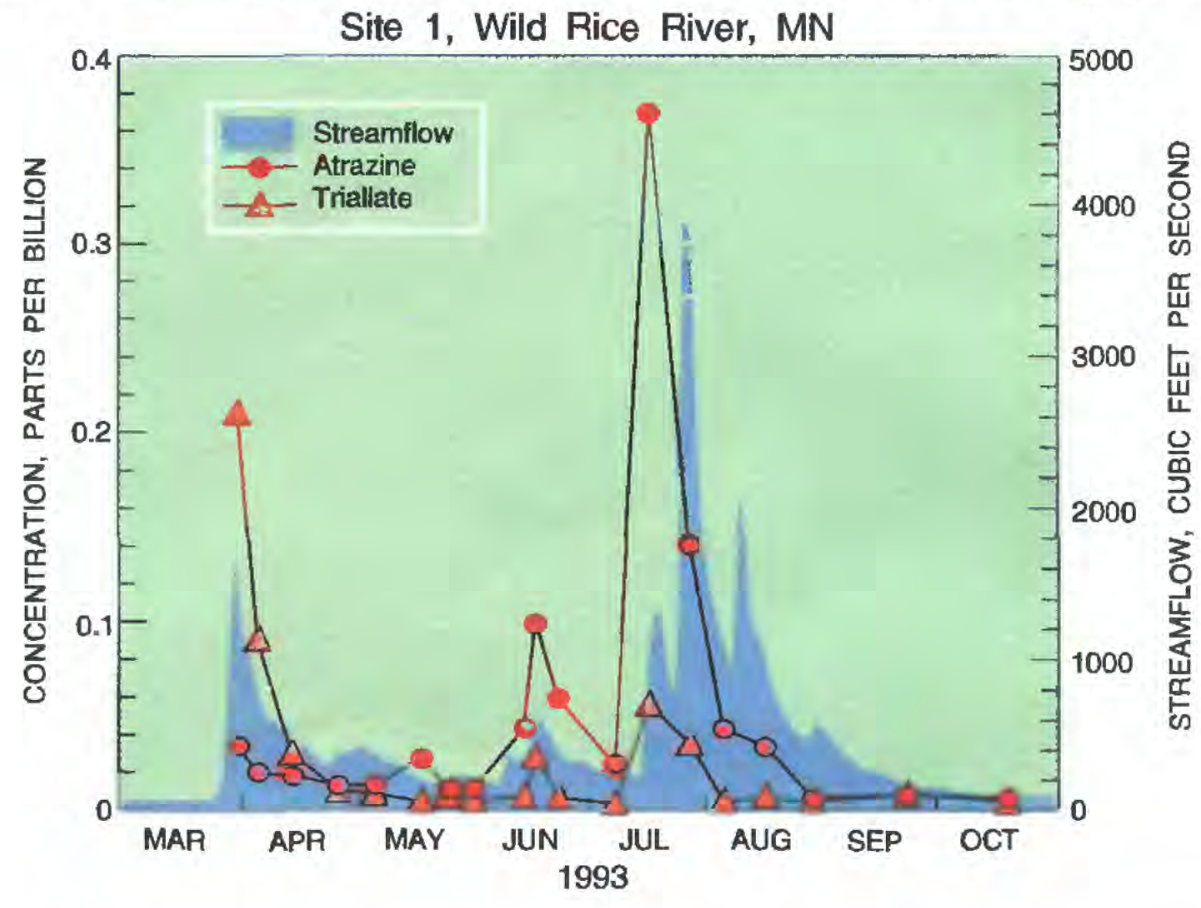

Atrazine concentrations at both sites were low or below detection during April and May, including spring snowmelt runoff. After late spring and early summer application, atrazine concentrations began to increase during increases in streamflow caused by rainfall runoff in June. During July, large amounts of runoff flushed atrazine into the streams, resulting in the highest atrazine concentrations measured in the stream that year. As increased runoff continued into August, atrazine concentrations declined, probably as the result of dilution and degradation. Similar patterns were observed for cyanazine and metolachlor.

Unlike atrazine, triallate concentrations were high in April during snowmelt runoff, then rapidly declined. During the summer, concentrations were negligible and often below detection. Triallate is an her- bicide that is applied mainly to winter wheat in the fall. These data indicate that residual herbicide from the previous fall application is washed into streams during snowmelt runoff and much less was available to wash into streams during the remainder of the year.

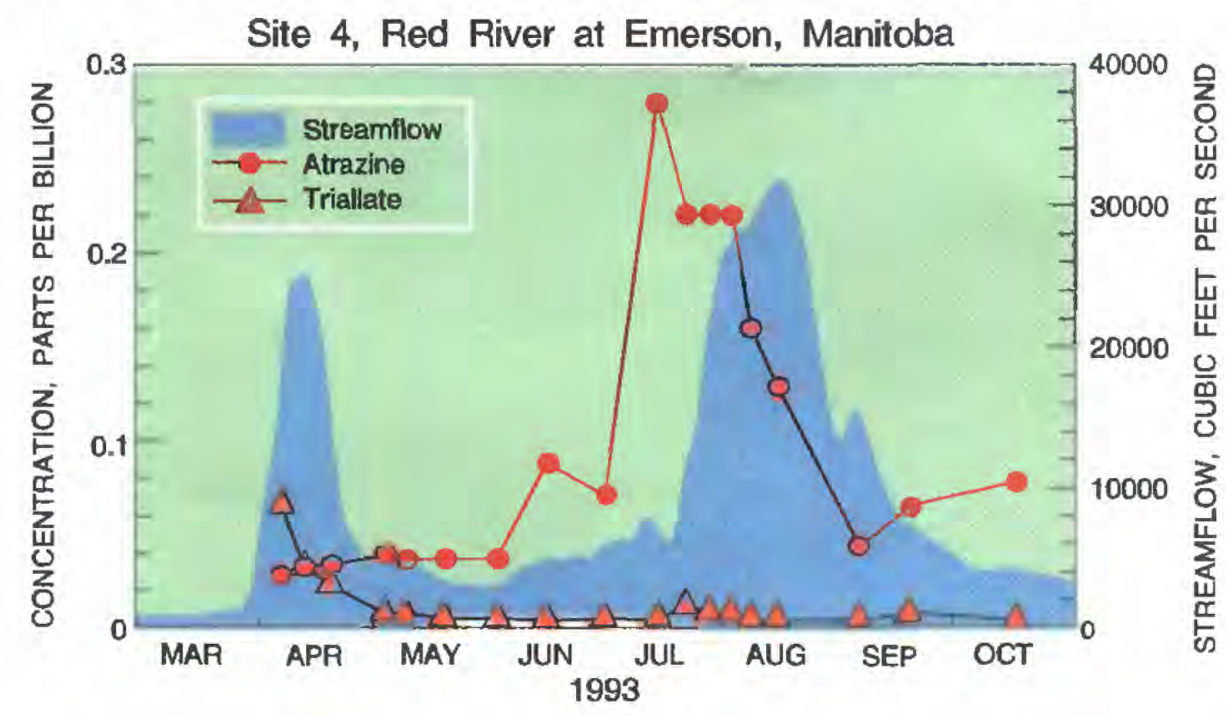

It is possible to estimate the proportion of frequently detected pesticides, such as atrazine, that are transported out of the basin in streamflow. Based on application rates estimated from 1992 crop statistics and estimating the annual atrazine yield leaving the basin from measurements of concentration and streamflow at the Canadian border during 1993, the following data result:

\section{Estimated atrazine application: 253,000 pounds Estimated atrazine yield: 1,340 pounds Percent leaving the basin: $0.5 \%$}

Similar calculations show that less than 2 percent of applied atrazine is transported from the Wild Rice, Turtle, and Snake River Basins (sites 1-3). The same is true of other agricultural chemicals that have been detected in the streams and that were evaluated using this approach.

It is not known why so little of the pesticides applied in the basin reach the streams. It is possible that flat slope, soils, and organic material limit the movement of the pesticides, or that microbial activity, sunlight, and climate cause rapid degradation of the pesticides.

\section{National Water Quallty Assessment Program}

The Red River of the North Basin is one of 20 study units started in 1991 as part of the U.S. Geological Survey National Water Quality Assessment program. The purpose of the program is to assess the quality of a large, representative part of the nation's waters. The first 20 study units focused on basins where agriculture is a significant part of the land use. In the Red River Basin about 64 percent of the land is used for crops.

A network of 15 sites (including the 5 discussed here) have been sampled from 1993 to 1995 . Samples have been analyzed for major ions (calcium, sodium, chloride, sulfate, etc.), nutrients (nitrogen and phosphorus), and organic carbon, with special emphasis on sampling high flows when runoff comprises a large part of the flow.

U.S. Geological Survey Open-File Report 95-283 Prepared by

L.H. Tornes and M.E. Brigham

For more information, contact:

Red River NAWQA Coordinator

U.S. Geological Survey

2280 Woodale Drive

Mounds View, Minnesota 55112

Phone (612) 783-3100 